\title{
El poblamiento prerromano en el área del Alto Tajo-Alto Jalón
}

\author{
The pre-Roman settlement in the Upper Tagus-Upper Jalón basins
}

\author{
J. Alberto Arenas Esteban \\ Universidad a Distancia de Madrid (UDIMA) \\ jesusalberto.arenas@udima.es
}

Recibido: 14-01-2011

Aceptado: 01-06-2011

\begin{abstract}
Resumen
En este trabajo se analiza la dinámica del poblamiento prerromano en el sector oriental de la Meseta. Aunque la información es todavía insuficiente, se ha intentado explicar la evolución de los distintos patrones reconocidos en función de los contextos socio-económicos en los que se insertaron. Desde esta perspectiva, aspectos como el presunto despoblamiento de la zona en el tránsito del II al I milenio BC, o la dualidad asentamiento indefenso en llano/asentamiento en altura fortificado, pueden ser explicadas en función de los cambios que, a lo largo de la Edad del Hierro, experimentaron las estrategias de producción y la configuración del grupo social. En términos generales, el proceso perceptible arranca de un hábitat disperso tendente a maximizar los rendimientos económicos en el marco de una economía estrictamente subsistencial. Más tarde, la estabilización territorial de la población dará lugar a la aparición de los enclaves fortificados en altura, cuya función básica fue la de "señalar" los ámbitos de comunidades concretas. Por último, la progresión demográfica y la apertura de la zona hacia territorios periféricos, reclamarán un proceso de intensificación productiva que, a la postre, desembocará en la aparición de los primeros oppida y, con ellos, de una organización de tipo urbano.
\end{abstract}

Palabras clave: Edad del Hierro. Territorio. Patrón de Asentamiento. Sociedad. Ideología.

\begin{abstract}
This paper analyzes the pre-Roman settlement dynamics in the eastern edge of the Spanish Plateau. Although information is still scarce, the differences in the observed patterns have been explained according to the specific socio-economic contexts in which they were embedded. Hence, issues such as the alleged depopulation of the area in the transition from the $2^{\text {nd }}$ to the $1^{\text {st }}$ millennium $B C$, or the dual model between undefended low-land sites and fortified up-land locations, can be explained in terms of changes that, throughout the Iron Age, experienced the productive strategies and the configuration of the social groups. In general terms, the perceptible process started with a scattered low-land habitat intended for maximizing economic benefits in the context of a strictly domestic economy. Later, the territorial stabilization of the population led to the emergence of the up-land fortified sites, whose basic function was to "signalize" the territory of specific communities. Finally, demographic increase and the opening of the area towards peripheral territories promoted a process of productive intensification which ultimately fostered the emergence of the first oppida, and with them, an urban-type organization.
\end{abstract}

KeY words: Iron Age. Territory. Settlement Pattern. Society. Ideology.

Sumario: 1. El proceso formativo: cabañas y "registros mudos". 2. Eventos para una estabilización: "esta tierra es mía”. 3. Expansión y heterogeneidad: "entonces ¿Esta tierra de quién es?”. 4. Los oppida y la política: hacia la disolución del orden tradicional. 
Este trabajo aborda el origen y posterior evolución del poblamiento estable en el área Alto Tajo-Alto Jalón; un sector del oriente meseteño que engloba las cabeceras de los ríos Tajo, Henares, Tajuña y Jalón, abarcando desde las estribaciones occidentales del Sistema Ibérico hasta el extremo oriental del Sistema Central (Fig. 1).

La zona posee unos rasgos orográficos heterogéneos, ya que mientras en la cuenca alta del Tajo el medio dominante son las agrestes sierras que configuran los Montes Universales y Sierra Molina - con alturas que superan los 2000 metros sobre el nivel del mar- el resto del territorio está caracterizado por un entorno de paramera a una altitud media de 1100 metros. Esta diversidad geográfica determina variaciones climáticas que se manifiestan en una progresiva continentalidad proporcional al aumento de altitud $y$, en consecuencia, diversos nichos ecológicos que condicionaron y condicionan sus potencialidades de explotación económica.
Figura 1.- Situación de los enclaves del área Alto Tajo-Alto Jalón citados en el texto:

1) Castilmontán (Somaén)

2) Alto de la Solana (Sagides)

3) La Coronilla (Velilla de Medinaceli)

4) La Cava (Luzón)

5) La Torre (Codes)

6) Cabeza del Molino (Mochales)

7) El Palomar (Aragoncillo)

8) Necrópolis de la Cerrada de los Santos (Aragoncillo)

9) El Turmielo (Aragoncillo)

10) Necrópolis del Molino (Herrería)

11) El Ceremeño (Herrería)

12) Necrópolis de la Riba de Saelices)

13) Peña Moñuz (Olmeda de Cobeta)

14) El Castellar (Berrueco)

15) Guisema (Tortuera)

16) Fuente Estaca (Embid)

17) Necrópolis de La Yunta

18) Los Rodiles (Cubillejo de la Sierra)

19) La Coronilla (Chera)

20) Castil de Griegos (Checa)

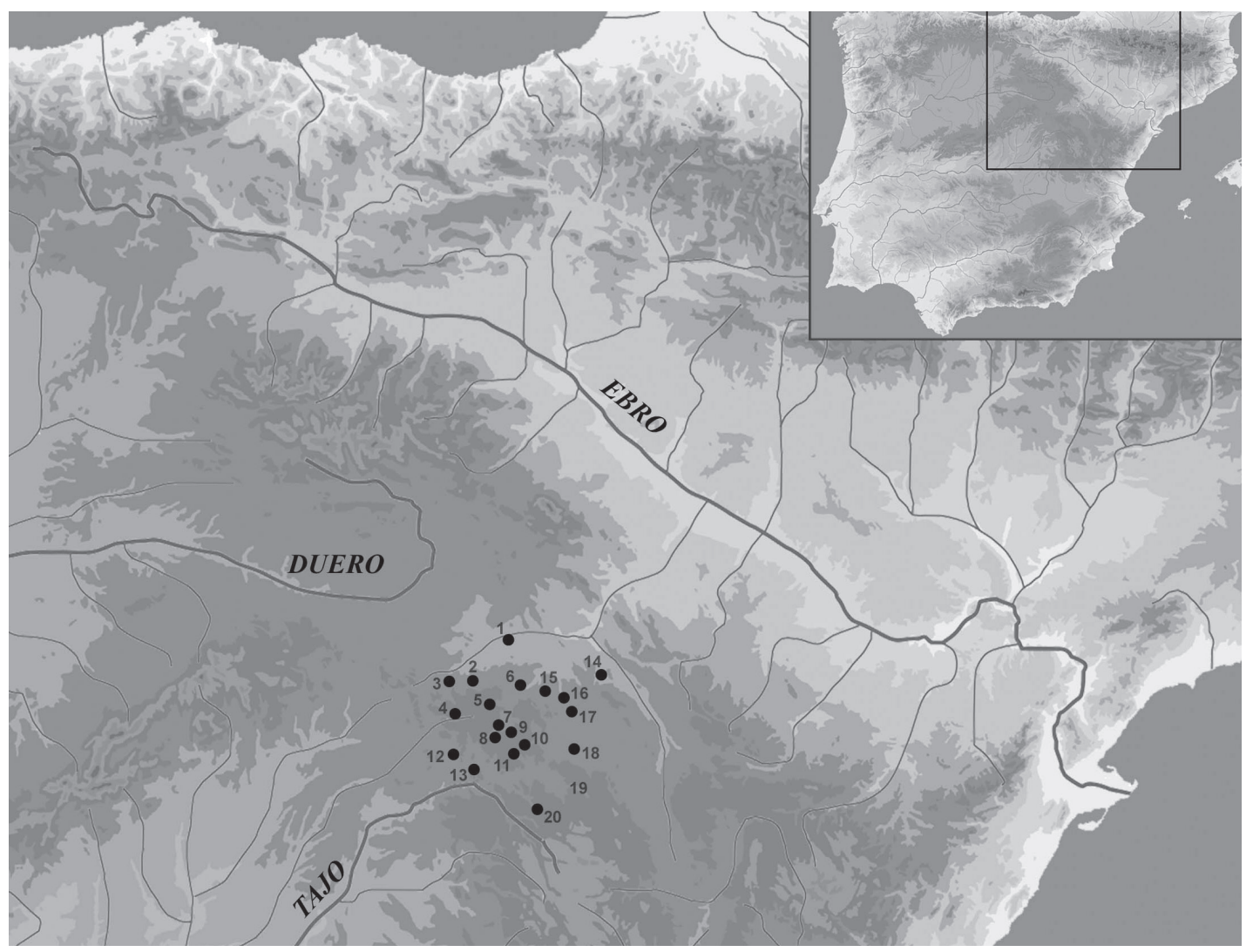


Desde una perspectiva arqueológica, nos encontramos en un área que en época prerromana estuvo ocupada por lo que la arqueología ha denominado tradicionalmente "Cultura del Alto Tajo-Alto Jalón" (Schüle 1969); una entidad emanada del estudio de distintas series de material protohistórico procedente de las necrópolis que hasta mediados del siglo XX se habían excavado intensamente. Pero a partir de la década de 1980 el interés investigador se desplazó hacia las áreas de hábitat, a la búsqueda de datos secuenciales que esas necrópolis ya por haber sido excavadas de antiguo, ya por encontrarse muy alteradas por las labores agrícolas modernas- eran incapaces de proporcionar. Este cambio comenzó a aportar un valioso flujo de información sobre las formas de vida de aquellas gentes, que se vio notablemente enriquecido por los análisis de los patrones de asentamiento que desde inicios de la década de 1990 se vienen desarrollando en la zona.

Sin embargo estos avances no lograron diversificar, al menos a corto plazo, la línea de trabajo que había imperado hasta entonces en la investigación sobre la protohistoria del Oriente meseteño; una línea que, a partir de criterios crono-tipológicos y las noticias aportadas por las Fuentes Clásicas, acuñó unas etiquetas culturales -como las de Campos de Urnas, Celtas o Celtíberos- en gran medida ajenas a la realidad de las comunidades que pretendemos estudiar.

Afortunadamente la postrera introducción en el discurso arqueológico de criterios interpretativos procedentes de la Sociología, la Antropología o la Ecología Cultural está dando como resultado un importante cambio de percepción del registro arqueológico respecto a las ópticas histórico-culturales comentadas arriba. Cada vez importa menos si esas gentes fueron celtíberos o no, o si un yacimiento ha de ser encuadrado en el periodo "Protoceltibérico" o en el "Celtibérico Antiguo". En cambio cada vez importa más saber por qué y para qué aquella gente construyó sus poblados como lo hizo o se enterró en sus necrópolis de la forma en que lo hizo. Y es desde esta perspectiva desde donde pretendo conectar con el tema del presente volumen.

Me dispongo a escribir sobre el poblamiento protohistórico del Oriente de la Meseta. Para ello podría ordenar cronológicamente los datos conocidos en materia urbanística y elaborar un cuadro descriptivo que muy probablemente tendría una validez limitada dado lo reducido de la muestra con la que nos vemos obligados a trabajar. Pero también podría poner sobre la mesa "todo lo poco" que sabemos de aquellas gentes, de forma que los datos sobre poblamiento cobrasen mayor significación al quedar conectados con el resto de las esferas que configuraron su sistema cultural. Y eso es lo que voy a hacer: intentar situar los distintos modelos de poblamiento detectados en la región del Alto Tajo-Alto Jalón en un contexto amplio, de forma que podamos entenderlos en los casos donde la evidencia sea categórica e intuirlos en aquellos donde la información sea débil o inexistente.

Para ello empiezo presentando el cuadro de la Figura 2, en el que quedan sintetizados los principales aspectos del proceso de cambio cultural experimentado por los grupos prerromanos del área Alto Tajo-Alto Jalón.

Evidentemente no es éste el lugar para desarrollar una explicación detallada de todos los registros incluidos en el esquema, pero su inserción en el presente trabajo permite vislumbrar sucesivos entornos socio-económicos, políticos e ideológicos en los que el poblamiento actúa como uno más de los parámetros involucrados. Estaremos así en una mejor posición para entender las transformaciones que aquellos patrones de asentamiento experimentaron tanto en su morfología externa como en su estructuración funcional y conceptual, así como la conexión existente entre las distintas modalidades de hábitat que se desarrollaron en cada una de esas "etapas". Por lo tanto, a lo largo de la exposición se intentará atender simultáneamente a todos estos parámetros, sin cuyo concurso no podríamos entender los casos concretos que se pretende analizar.

Como punto de partida, cabría llamar la atención sobre las dos modalidades de poblamiento genéricas que se perfilan en todo el proceso: una fase de poblamiento disperso y basado en agrupaciones indefensas de cabañas y, más tarde, un poblamiento concentrado materializado en la aparición del asentamiento fortificado en altura. 


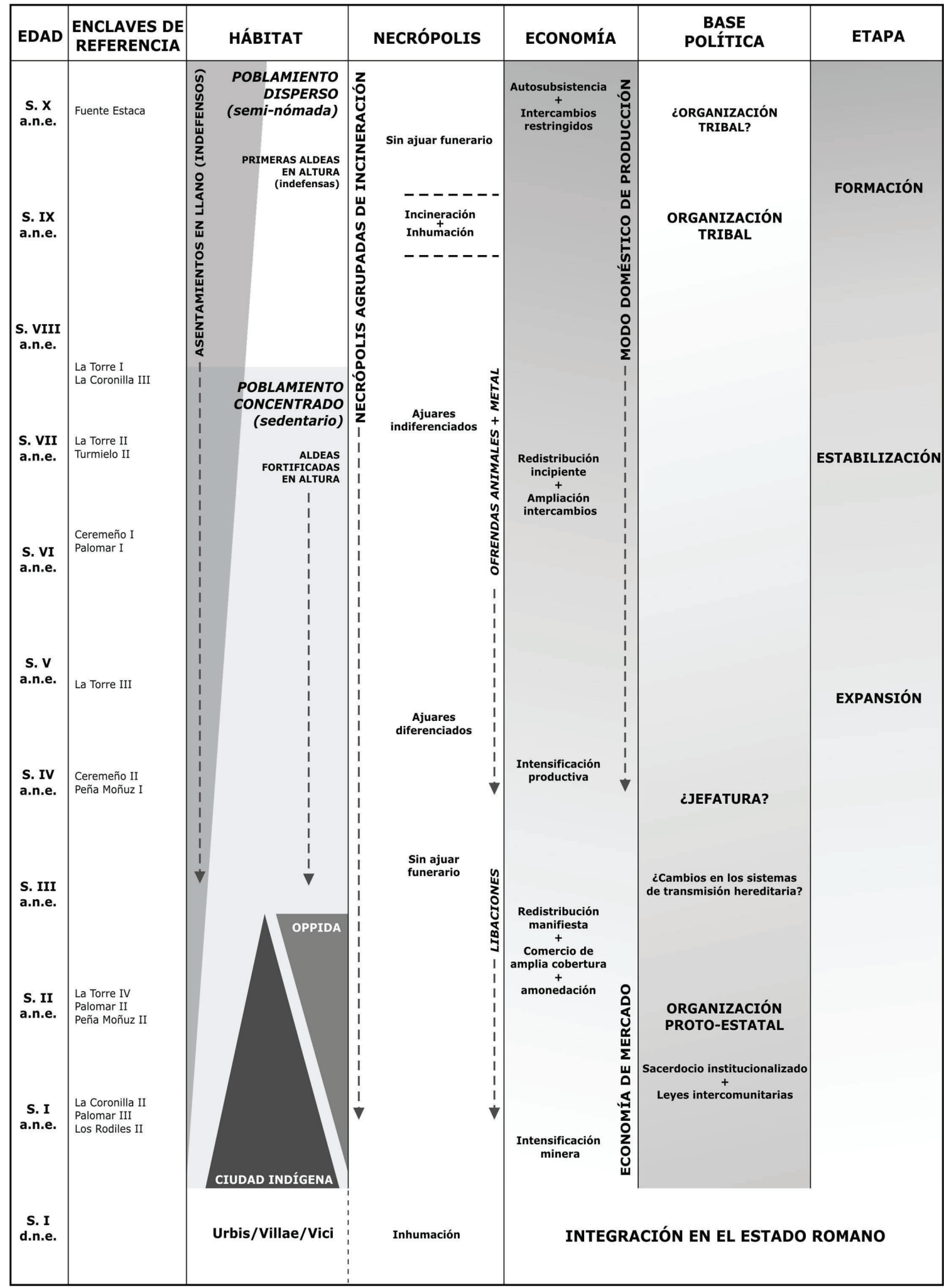

Figura 2.- Esquema general del marco cultural protohistórico en el área Alto Tajo-Alto Jalón. 
Y la cuestión básica es explicar cómo y por qué el primero es sustituido por el segundo, convirtiéndose -desde su aparición en el siglo VII a.C. hasta la irrupción de Roma en la primera mitad del siglo II a.C. - en el modelo habitacional dominante.

Pero al mismo tiempo, es también necesario tratar un aspecto no menos importante: que esa uniformidad en el poblamiento es sólo aparente, ya que a nivel interno; es decir, en lo que atañe a su perfil sociológico y articulación conceptual, esos espacios protourbanos comúnmente denominados "castros" se revelan como unidades muy versátiles cuyo significado ha variado sustancialmente a lo largo del tiempo.

\section{El proceso formativo: cabañas y "registros mudos"}

Ante la ausencia de información sobre un poblamiento significativo durante la segunda mitad del II milenio a.C., en anteriores trabajos he defendido la idea de que la génesis del poblamiento protohistórico en el área del Alto Tajo-Alto Jalón fue un fenómeno atribuible a factores básicamente exógenos (Arenas 1997, 1999a, 1999b).

Sin embargo, recientes descubrimientos efectuados en la zona obligan a matizar esta postura porque, aunque es cierto que no conocemos prácticamente ningún asentamiento datable en la segunda mitad del II milenio a.C., ambientes como el nivel inferior de la necrópolis de Herrería -Herrería I- demuestran no sólo que la zona estuvo habitada al menos desde el siglo XII a.C. (Cerdeño y Sagardoy 2007: 31 ), sino que sus pobladores gozaron del suficiente grado de estabilidad como para generar necrópolis de cierta envergadura, con un claro interés de perduración y, sobre todo, de visualización social a juzgar por las estelas pétreas con las que fueron señaladas sus sepulturas.

Esto obliga a pensar que la comunidad que generó tal cementerio estuvo radicada en el área, aunque de una forma distinta a como lo estuvieron los futuros grupos protohistóricos. Efectivamente, la presencia de una necrópolis con más de 60 sepulturas no puede ser fruto sino de una ocupación continuada del territorio, pero la invisibilidad de sus entornos ha- bitacionales ha de ser atribuida a un régimen socio-económico específico en el que la clave debió ser, bien un elevado índice de dispersión poblacional, bien una alta movilidad a nivel local -0 muy posiblemente ambas. Tales rasgos pudieron determinar un tipo de arquitectura endeble de bajo impacto en el entorno físico; y pudieron determinar también un patrón de asentamiento heterogéneo que impidió la configuración de un hábitat tipificable, que es a lo que estamos acostumbrados y lo que hemos estado buscando todos estos años.

Además, el nivel fundacional de la mencionada necrópolis de Herrería ofrece otro importante punto de reflexión: exceptuando algunos elementos de industria lítica, las sepulturas carecían de ajuar funerario ya fuese cerámico o metálico. Esto induce a pensar que nos encontramos ante grupos que produjeron una cultura material igualmente "atípica" -en el sentido de que no muestra elementos diagnósticos claramente reconocibles-, lo que nos situaría ante un "registro arqueológico mudo" en superficie, inasequible a nuestro conocimiento si no es por medio de la excavación arqueológica.

Quizá lo expuesto hasta aquí es todo lo que se pueda decir por ahora sobre este horizonte de poblamiento. Pero una vez reconocido este hecho, es necesario indagar en el proceso de cambio que acabará resolviéndose en la emergencia de los patrones de asentamiento característicos de la Protohistoria regional; esta vez ya perfectamente reconocibles en el registro arqueológico incluso superficial.

En los trabajos previos ya citados se proponía que el inicio del proceso pudo estar relacionado con la convergencia en el área de reducidos grupos humanos de distinta procedencia que, interactuando entre los siglos $\mathrm{X}$ y VIII a.C. configuraron los precedentes inmediatos de la futura Edad del Hierro local. Esta idea se sustentaba en la presencia de una serie de establecimientos en llano que representan los exponentes más antiguos de la secuencia protohistórica "arqueológicamente perceptible" en el área Alto Tajo-Alto Jalón (Arenas 1997; Crespo Cano y Arenas 1998), aunque actualmente contamos con argumentos de refuerzo procedentes del mundo funerario. 
Comenzando por éste último, volvemos a encontrar un valioso referente en la segunda fase de utilización de la Necrópolis de Herrería-Herrería II-, dos de cuyas sepulturas han aportado dataciones del $961 \mathrm{cal} \mathrm{BC} \mathrm{y} 831 \mathrm{cal}$ BC (Cerdeño y Sagardoy 2007: 32-33). En este momento se advierten importantes novedades respecto a la fase precedente: el número de sepulturas se eleva a 239 , lo que indica una intensificación -ya fuese en términos temporales o demográficos- en el uso del cementerio; el paisaje funerario se transforma radicalmente debido a la aparición de estructuras tumulares como elementos señalizadores; entre el ritual dominante de la incineración, aparecen cinco individuos inhumados cuya sepultura adopta una configuración diferenciada del resto; por último, y aunque escasos, aparecen los ajuares cerámicos y metálicos, que incluyen recipientes a mano con esquemas decorativos perfectamente paralelizables a los que se van a documentar en los espacios habitacionales coetáneos.

En el plano habitacional, el conjunto de evidencias conocido ha sido englobado bajo la denominación de "Horizonte Fuente Estaca", a partir del yacimiento epónimo excavado en Embid a finales de la década de 1980 y todavía publicado muy fragmentariamente (Martínez Sastre 1992). Los enclaves de este tipo son asentamientos de pequeñas dimensiones -algunos de ellos constituidos por una única estructura de habitación-, se ubican siempre en zonas llanas aptas para la agricultura y carecen tanto de un urbanismo definido como de recursos defensivos. En el caso de Fuente Estaca, con una fecha radiométrica de 919 cal BC (Castro Martínez et al. 1996: apéndice Tabla de Dataciones), se excavaron dos sectores en los que se localizaron los restos de sendas cabañas construidas con postes de madera y manteo de barro con abundante material arqueológico en su interior (Fig. 3), si bien éste último era completamente diferente en ambos sectores. La precariedad constructiva unida a las comentadas diferencias mobiliares sugieren que nos encontramos ante ocupaciones recurrentes, quizá de carácter estacional, que pudieron prolongarse durante periodos de tiempo relativamente largos e incluso vincularse a grupos de distinta procedencia o perfil cultural.
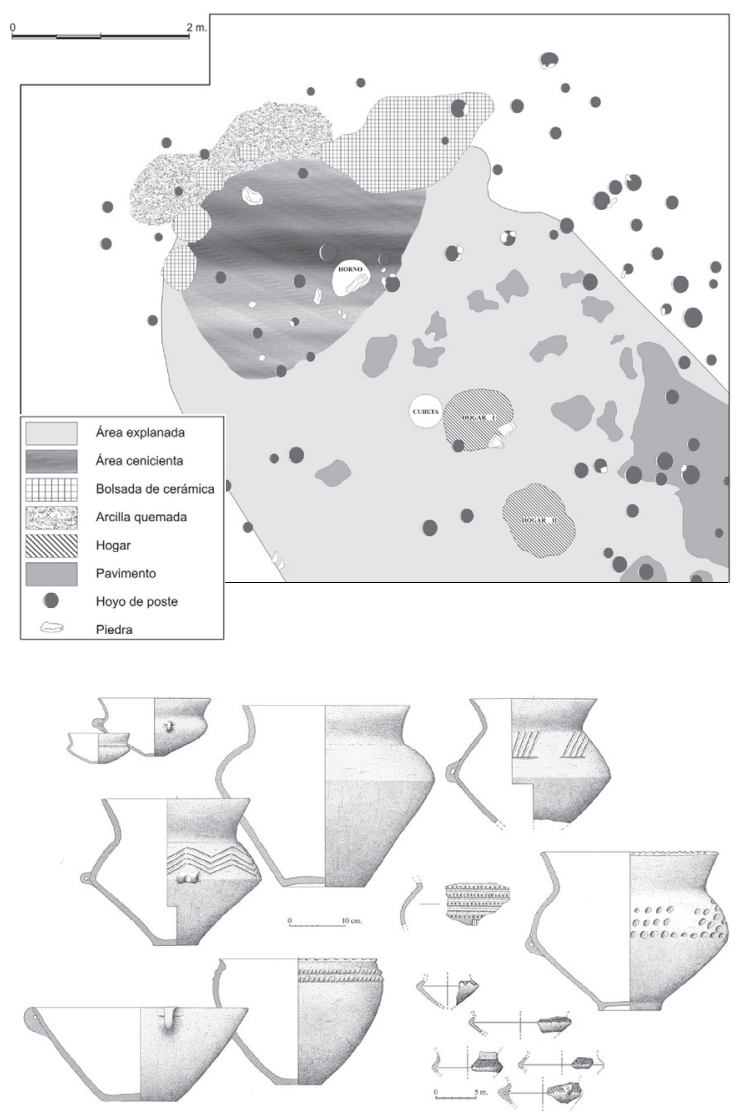

Figura 3.- Planta de la cabaña excavada en el sector I de Fuente Estaca y selección de material cerámico hallado alrededor del horno.

Poco se puede decir por el momento de los esquemas socio-económicos que desarrollaron esas comunidades. Debieron ser grupos de reducidas dimensiones en los que la familia extensa constituiría el grupo primario de subsistencia sobre una base marcadamente igualitaria, a juzgar por la homogeneidad de los ajuares en las sepulturas de esta época.

Por otra parte, la presencia de un horno cerámico - con toda una hornada de piezas hallada a su alrededor- en la cabaña del Sector I de Fuente Estaca sugiere un régimen productivo autosuficiente $\mathrm{y}$, por extensión, una elevada autonomía de sus moradores.

Además, la precariedad de este tipo de hábitat - carente de defensas y urbanismo-y de sus planteamientos arquitectónicos hace pensar que estas comunidades mantuvieron una alta movilidad territorial para poder optimizar 
el acceso a distintos recursos y minimizar la competencia por los mismos. De hecho, desde que fue dado a conocer en la bibliografía especializada el número de yacimientos de este tipo ha aumentado de 11 a más de 40, y sus nichos ecológicos han rebasado las zonas agrícolas para ocupar también áreas de sierra con perores condiciones agronómicas pero mucho mejor situadas en relación con vías de comunicación así como pastos/recursos forestales y mineros. Desde esta perspectiva, el emplazamiento específico de cada uno de estos enclaves podría haber estado vinculado a la explotación periódica de recursos mayoritariamente agropecuarios o mineros (Jimeno y Arlegui 1995: 103-105; Martínez Naranjo 1997: 165).

Este modelo, que hasta hace poco podría haber parecido inusual, es hoy en día relativamente bien conocido en el centro de la Península Ibérica. Efectivamente, la existencia de regímenes socioeconómicos de perfil itinerante se está empezando a conocer en la Meseta Norte (Misiego et alii 2005) y, sobre todo, en el valle medio del Tajo, donde en los últimos años se han excavado varios asentamientos constituidos por agrupaciones de cabañas similares a las documentadas en el Alto TajoAlto Jalón. Dejando al margen casos ciertamente inusuales como las long houses documentadas en Las Camas de Villaverde (Urbina et al. 2007), el horizonte que se nos presenta es el de una red de poblados cuya estructura espacial y secuencia estratigráfica indican un alto grado de movilidad territorial (Blasco Bosqued 2007: 70; Martín Bañón 2007: 37) que también se refleja en su oferta material, ya que incorporan elementos formales vinculados a distintas corrientes culturales y áreas geográficas de la Península. Esta lectura también resulta factible para los asentamientos del Alto Tajo-Alto Jalón, de donde proceden algunos elementos suntuarios de ascendencia mediterránea (Arenas 1999a: 176 y Fig. 121) que hablan de contactos con el exterior que pudieron verse incentivados $\mathrm{y} / \mathrm{o}$ facilitados por la movilidad de sus ocupantes.

Pero a pesar de todo lo expuesto hasta el momento, existen razones para pensar que el tipo de hábitat que representan los poblados de tipo Fuente Estaca no fue el único existente en la zona durante el tránsito del II al I milenio a.C., ya que han empezado a detectarse enclaves emplazados en la cima de cerros aislados donde las evidencias superficiales también parecen indicar la presencia de una arquitectura efímera así como la inexistencia de defensas. Este rasgo, junto a la presencia de elementos como fíbulas de tipo "Ría de Huelva" (Cebolla Berlanga 1992-93: 185) apunta hacia una cronología y ambiente cultural similares a los de los asentamientos en llano descritos.

Algunos de estos asentamientos fueron de tamaño modesto, como es el caso del Castillejo de Fuensaúco, con una datación de 827 cal BC (Romero Carnicero 1999) y, quizá, del nivel fundacional de La Coronilla de Chera (Cerdeño y García Huerta 1992) con una datación radiométrica de 1112 cal BC (Castro Martínez et al. 1996: apéndice Tabla de Dataciones), aunque la presencia de estructuras pétreas en el mencionado nivel podrían invalidar esta hipótesis. Pero junto a éstos, también se conocen otros de mayores dimensiones en los cursos altos de los ríos Mesa - como Cabeza del Molino en Mochales (Cebolla 1992-93: 176)- y Jalón -Alto de la Solana de Sagides y La Coronilla de Vellilla de Medinaceli (Martínez Naranjo 1997: 168 y ss.), desgraciadamente todavía sin excavar.

Este esquema de poblado abierto ubicado en la cima de grandes cerros remite a modelos documentados en zonas cercanas como el valle del Henares con yacimientos como La Muela de Alarilla (Méndez y Velasco 1988) o Ecce Homo de Alcalá de Henares (AlmagroGorbea y Fernández-Galiano 1980; AlmagroGorbea y Dávila 1988), y podría estar indicando la existencia de comunidades de cierta envergadura y complejidad socio-económica que, por razones todavía difíciles de precisar, empiezan a mostrar un interés bien por aislarse y defenderse, bien por controlar secciones de territorio concretas.

En cualquier caso, e independientemente de los matices introducidos ahora en el discurso, el poblamiento sustentado en asentamientos abiertos con arquitectura endeble se prolonga hasta aproximadamente inicios del siglo VII a.C., momento en el que tiene lugar un cambio brusco y, aparentemente, culminado en un corto lapso temporal. Aparece 
entonces un hábitat permanente materializado en los siguientes aspectos:

$\left.1^{\circ}\right)$ El hábitat en altura se convierte en el patrón dominante.

$2^{\circ}$ ) Las cabañas de postes de madera se sustituyen por sólidas estructuras angulares, construidas con zócalo de piedra y recrecido de adobe.

$3^{\circ}$ ) Se verifica un importante incremento del número de poblados.

$\left.4^{\circ}\right)$ Esos nuevos enclaves, casi todos de nueva planta y ubicados en lugares altos, son protegidos por cerramientos perimetrales de complejidad variable.

$5^{\circ}$ ) Por último, se generalizan las necrópolis de incineración con enterramientos ya asociados a nutridos ajuares cerámicos y metálicos, vinculadas en la mayoría de los casos a poblados concretos con los que guardan una perfecta relación de vecindad.

\section{Eventos para una estabilización: "esta tierra es mía”}

Establecer las causas de esta ruptura no es fácil. Los factores medio-ambientales debieron jugar un papel secundario -si es que jugaron alguno- ya que tras el periodo frío registrado en el tránsito del II al I milenio a.C., es precisamente en el siglo VII a.C. cuando los indicadores paleoclimáticos señalan un paulatino calentamiento que irá reduciendo las limitaciones de las tierras altas peninsulares como la que ahora nos ocupa (Ibáñez González 1999: 26). Por otra parte, la contundencia y rapidez del cambio junto al notable incremento del número de asentamientos podrían hacer pensar en un aumento demográfico, pero esta posibilidad parece poco plausible, primero porque el periodo de tiempo en el que se operan tales cambios es demasiado corto -quizá menos de una centuriacomo para permitir un significativo crecimiento natural de la población $\mathrm{y}$, segundo, porque no existen indicadores de aportes demográficos sustanciales procedentes del exterior.

Por estas razones, parece más verosímil pensar que en el área Alto Tajo-Alto Jalón es- tas novedades fuesen el producto de una reorganización de las estrategias productivas y sociales de los grupos que hasta ese momento habían practicado formas de vida más o menos itinerante. El motor del cambio pudo ser la actividad que a todos los niveles registra la periferia peninsular durante el siglo VII a.C., relacionada con el fenómeno colonial y que en el seno de las sociedades indígenas no sólo supuso un periodo de cambio social y renovación tecnológica, sino también de captación de nuevos ámbitos productivos como pudieron ser las Serranías Ibéricas, donde ciertos recursos naturales -metalúrgicos y pecuarios sobre todohabían permanecido infraexplotados (Arenas 2004: 160).

Sea como fuere, lo cierto es que durante el siglo VII a.C. cristaliza en el área un complejo cultural de marcada personalidad que define la etapa inicial de la Edad del Hierro regional. Es entonces cuando se adoptan las formas de hábitat que van a ser típicamente protohistóricas, capitalizadas por el poblado fortificado en altura. Es también entonces cuando, en el plano de la cultura material, el horizonte cerámico característico de momentos anteriores se ve sustituido por otro en el que dominan los ejemplares lisos aunque, a pequeña escala, se decorasen mediante grafitado y pintura postcocción. También hace entonces su aparición la cerámica a torno de origen mediterráneo; al igual que algunos de los elementos metálicos más característicos del inicio de la Edad del Hierro en la región como son las fíbulas de doble resorte y los broches de cinturón de tipo orientalizante. Incluso es muy posible que algo tan trascendental como la siderurgia hiciese su aparición en estos momentos, a juzgar por la presencia de objetos de hierro en sepulturas datables en esta época de necrópolis como La Cerrada de los Santos de Aragoncillo (Arenas Esteban 1999a: 181) o el Nivel III de El Molino de Herrería (Cerdeño y Sagardoy 2007: 133-135).

En esencia, creo que lo que se percibe es la progresiva Estabilización territorial de unas comunidades que hasta ese momento habían mantenido un bajo nivel de integración socioeconómica; unas comunidades que, ante los estímulos procedentes de territorios periféricos, hubieron de "reinventar" su sociedad y su economía, adaptándose a una nueva realidad 


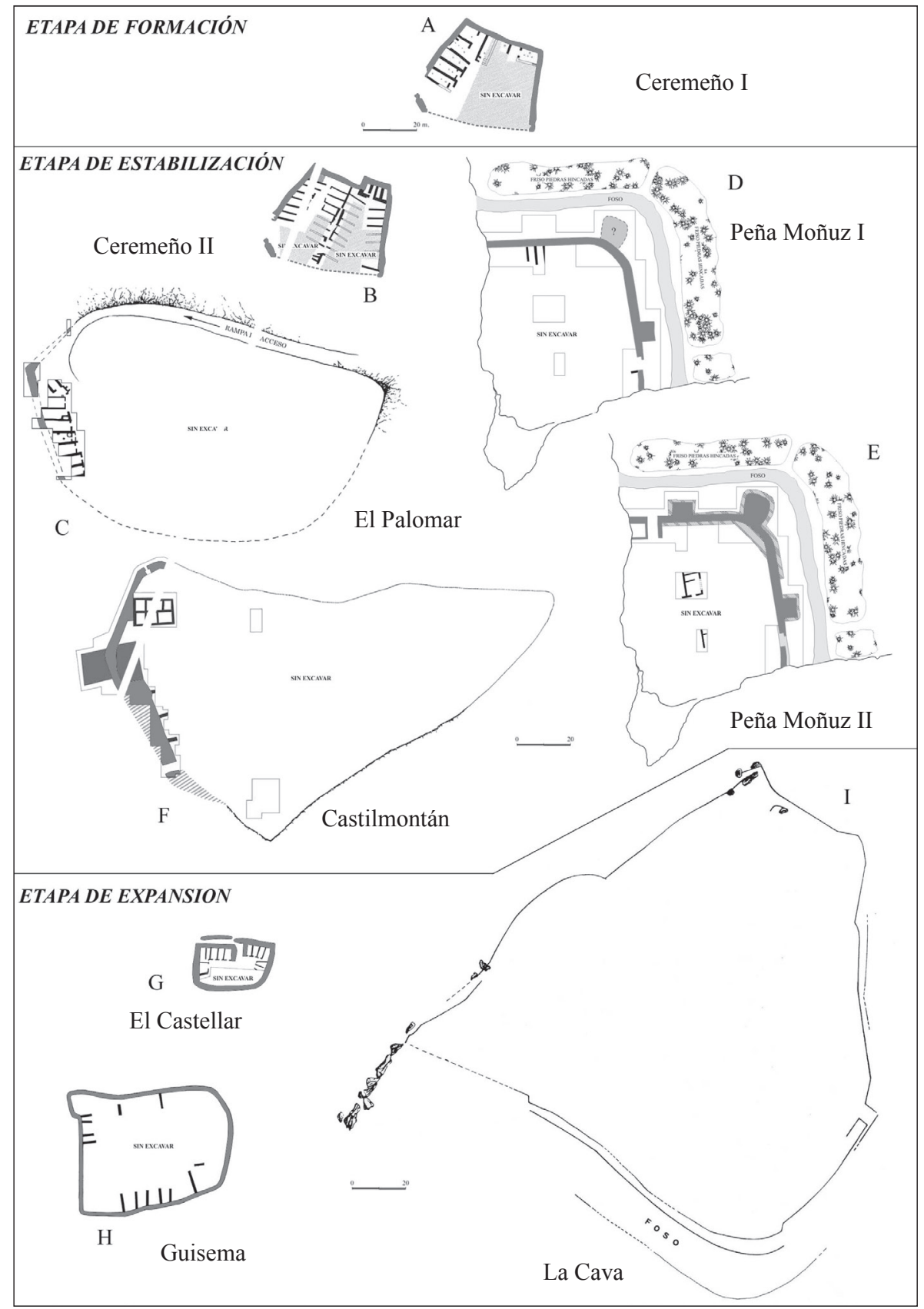

Figura 4.- Plantas de asentamientos protohistóricos del área Alto Tajo-Alto Jalón: a) (según Cerdeño y Juez 2002); b) (según Cerdeño y Juez 2002); c) (según Arenas 1999a); d) (inédito);e) (inédito); f) (según Arlegui 1992); g) (según Polo y Villagordo 2004); h) (inédito); i) La Cava (según Iglesias et al. 1989).

utilizando dos elementos fundamentales: el poblado fortificado como lugar de hábitat y la necrópolis cerrada como referente ideológico, conectados ambos por la necesidad de una expresión social colectiva.
En este contexto, la aparición de poblados en puntos prominentes podría relacionarse con una reestructuración del paisaje de carácter tanto práctica como simbólica: la rápida proliferación de asentamientos debió exigir la 
definición de sus respectivos ámbitos de influencia y sus correspondientes demarcaciones territoriales, que pudieron quedar establecidas, precisamente, mediante el nuevo tipo de hábitat individualizado en el entorno físico. Sería un fenómeno similar al que con anterioridad tuvo lugar en las costas de Cataluña y el Levante septentrional, cuando la llegada de una nueva población de Campos de Urnas primero, y del elemento colonial más tarde, provocaron un proceso relativamente rápido de territorialización basado en la apropiación tanto física como simbólica del espacio (Rovira i Port 1990-91: 169; Sanmartí y Santacana 2005: 43-46) con unas consecuencias similares: la aparición del hábitat en altura de carácter estable en el plano básicamente utilitario y de su correlato ideológico en las necrópolis cerradas de incineración con ajuares funerarios definidos y diferenciados (Ortega Ortega 1999a: 112-113).

Con la generalización de este tipo de asentamiento queda instaurado un modelo habitacional que, en sus rasgos generales, va a perdurar durante toda la Edad del Hierro. Se trata de entornos concebidos para la vida sedentaria cuya fisonomía fue planificada antes de su construcción a partir de un cálculo previo del espacio necesario para albergar un número concreto de personas y actividades. Quedaba así cubierta una buena parte de las necesidades subsistenciales de la comunidad: desde la vivienda propiamente dicha hasta las actividades productivas y de reproducción social.

$\mathrm{Su}$ configuración es variable (Fig. 4) ya que las plantas suelen adaptase a las condiciones topográficas del terreno. Como demuestran las excavaciones practicadas en yacimientos como $\mathrm{La}$ Coronilla de Chera (Cerdeño y García Huerta 1992), El Palomar de Aragoncillo (Arenas 1999a) o El Ceremeño de Herrería (Cerdeño y Juez 2002), las construcciones se adosan al muro de cierre externo, dejando un espacio abierto central de uso probablemente colectivo. Son edificios de planta angular con un módulo heterogéneo que produce espacios de diversa morfología y que rara vez rebasan los 40-50 $\mathrm{m}^{2}$ de superficie útil. De hecho, en estos momentos las unidades domésticas alcanzan cierta complejidad dado que parecen estar compuestas por varios edículos de distinta funcionalidad. Además, el hecho de que se articulen conforme a un planteamiento horizontal -no se han registrado indicios de segundas plantas- supone que la cantidad de espacio requerida por cada grupo familiar sea relativamente alta. No obstante, y a pesar de esta heterogeneidad, puede vislumbrarse cierto equilibrio tanto entre el espacio residencial y productivo como entre el privado y el público, lo que debería haber facilitado unas relaciones sociales fluidas (Arenas 2010).

Estos asentamientos suelen ser de pequeñas dimensiones -muy pocas veces superan la hectárea de superficie- de lo que se desprende que albergaron comunidades modestas. Además casi nunca fueron objeto de ampliaciones, lo que ha sido interpretado como la expresión material de grupos de tipo segmentario (Ortega 1999b; Burillo y Ortega 1999: 130). Todo esto permite vislumbrar una organización socio-política de perfil tribal, presumiblemente poco jerarquizada a juzgar por la limitada diferenciación perceptible en los ajuares funerarios (Arenas 1999a: 239-240).

En el plano macroespacial, durante la etapa de estabilización los poblados se diseminaron uniformemente por el paisaje, del que controlaron segmentos concretos. Los datos disponibles parecen indicar que practicaron una economía de alcance básicamente familiar, vertebrada en torno al poblado en altura como núcleo residencial más importante, a menudo asociado a uno o varios enclaves en llano que, en lugar de ser unidades autosuficientes como en la etapa anterior, parecen mantener una relación esencialmente complementaria en materia social y económica con los primeros. Por esta razón es posible pensar que sus respectivos habitantes fueron meros segmentos de una misma comunidad, o, expresado en términos más genéricos, que el concepto de comunidad rebasó en aquellos momentos los límites físicos del asentamiento individual extendiéndose a distintos puntos en un microterritorio específico (Arenas 2009: 219).

Y esta homogeneidad relativa también parece plasmarse en el acceso a bienes exóticos o de consumo restringido. Todos los entornos residenciales de esta época excavados han aportado elementos de origen foráneo (Cerdeño et al. 1996; Arenas 1999c), cuya llegada pudo realizarse por medio de redes de intercambio interno entre los distintos asentamientos o -con menos probabilidad- a través de contactos directos de cada uno de estos poblados con el exterior. A 
este respecto, un caso sobresaliente es el de El Turmielo de Aragoncillo: un enclave de reducidas dimensiones, desvinculado tanto de terrenos cultivables como de vías de comunicación, pero controlando de forma directa el acceso a una zona rica en recursos metálicos -hierro, cobre y plata, sobre todo-. Posiblemente esta sea la causa de la riqueza que ha deparado su nivel de ocupación del Hierro Inicial, en el que además de importantes excedentes agrícolas, se han documentado piezas metálicas y cerámicas de origen alóctono (Arenas y Martínez 1993-95).

\section{Expansión y heterogeneidad: "entonces ¿esta tierra de quién es?"}

A partir del siglo $\mathrm{V}$ a.C. entramos en una nueva etapa que podría calificarse de Expansión, socio-económica en general y del poblamiento en particular.

Por lo que respecta a éste último, el registro arqueológico muestra una mayor variabilidad morfológica respecto a momentos anteriores derivada de una diversificación topo-funcional. $\mathrm{Si}$ bien es cierto que algunos enclaves como El Palomar de Aragoncillo (Fig. 4-C) o Peña Moñuz I (Fig. 4-D) perpetúan el esquema de construcciones perimetrales en torno a un espacio central, también lo es que surgen importantes novedades en lo que respecta a la organización interna de los asentamientos.

Por una parte, conocemos una serie de enclaves ya establecidos en la Primera Edad del Hierro que, mientras su perímetro exterior permanece inalterado o con mínimos cambios respecto a su trazado original, experimentan profundas transformaciones en su estructura interna. Aparece ahora un nuevo concepto organizativo plasmado en filas de habitáculos adosados unos a otros, construidos con un módulo uniforme, a la vez que el tradicional espacio central es sustituido en algunos casos por ejes longitudinales que, a modo de calles, conservan un carácter público. Ejemplo de ello vuelve a ser el caso de El Ceremeño, en cuya segunda fase (Fig. 4-B) el espacio central que antes había permanecido vacío se amortiza con una densa red de construcciones, lo que no sólo evidencia un cambio radical en el concepto y uso del espacio doméstico, sino que también pudo dar lugar a un aumento de la tensión social en la comunidad residente (Arenas 2007).

Otro caso interesante es el del poblado de Peña Moñuz; un enclave fundado entre los siglos IV-III y abandonado a principios del II a.C., y en el que se han documentado dos fases de ocupación separadas por un violento incendio. En la primera de ellas, se construye un potente sistema defensivo a cuyo interior los edificios parecen seguir el sistema perimetral característico de la Primera Edad del Hierro (Fig. 4-D). En cambio en la segunda fase, esas construcciones son abandonadas, pasándose a ocupar la parte central del yacimiento con edificios aparentemente exentos (Fig. 4-E) que, aunque no dejen de tener un carácter residencial, muestran una clara especialización funcional, en este caso relacionada con el almacenamiento y procesado de productos agrícolas.

Este último yacimiento nos permite conectar con otro tema importante: la aparición en esta época de los primeros programas arquitectónicos de carácter decididamente monumental y que se manifiestan en dos ámbitos distintos.

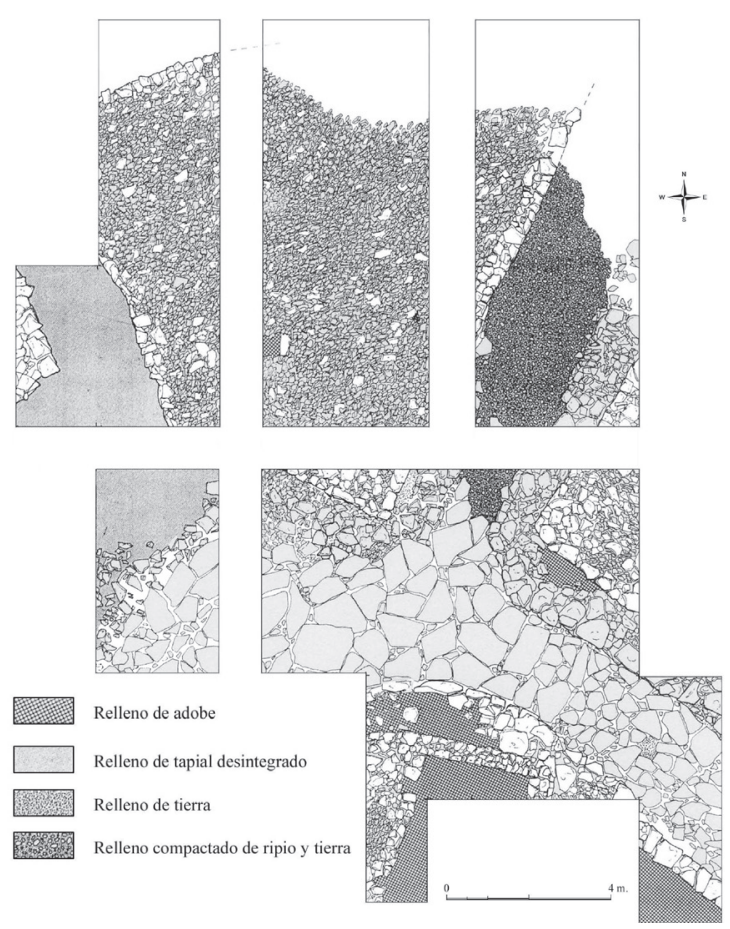

Figura 5.- Planimetría del sector excavado de La Torre IV de Codes (según Arenas 1999a) 
Por una parte aparecen una serie de asentamientos dotados de sistemas defensivos con una envergadura y monumentalidad nunca antes percibida. Tanto Peña Moñuz como el cercano enclave de El Hocincavero en Anguita (Barroso y Díaz 1999) se rodean de murallas con más de tres metros de grosor y cuatro de altura conservada, flanqueadas en su cara externa por torres macizas de planta rectangular, a lo que había que unir recursos complementarios como son fosos y frisos de piedras hincadas así como sistemas de acceso complejos.

Por otra, se detectan también ahora los primeros intentos de saneamiento y monumentalización de los espacios interiores de esos poblados. Y para ilustrarlo baste otro ejemplo: el del poblado de La Torre de Codes, en cuya fase del siglo III a.C. se construye una calle enlosada de desarrollo perimetral (Fig. 5) sin parangón en todos los enclaves de esta época excavados en el reborde oriental de la Meseta (Arenas 1999a: 68 y ss.).

A nivel regional, los asentamientos se reparten ahora desigualmente por el territorio, lo que puede ser interpretado como una ocupación selectiva en función de requerimientos económicos o geo-estratégicos; concretos, lo que apunta hacia un control sobre territorios más amplios que en la etapa anterior. El aludido aumento de la superficie construida en los asentamientos puede interpretarse de dos maneras: como un incremento demográfico o, más probablemente, como una intensificación productiva que exige la ampliación de una "arquitectura auxiliar" -graneros, establos, talleres, etc.-. Y quizá con ello cabría relacionar los indicios de producción artesanal especializada que ahora se detectan en su interior. Ya se ha comentado el caso de los espacios dedicados a la gestión de productos agrícolas de Peña Moñuz, al que habría que unir las posibles evidencias de elaboración y almacenaje in situ de excedentes cárnicos (Arenas Esteban 1999c: 304-305) y de actividad siderúrgica (Naranjo y Arenas 1999: 206) documentadas en El Palomar de Aragoncillo. Estos datos nos remiten a cuadros económicos más diversificados, con un enfoque excedentario tendente al desarrollo de intercambios tanto internos como externos, que se plasman en la proliferación de bienes exóticos en los ajuares funerarios y en el incre- mento de alimentos y bebidas de producción foránea como son por ejemplo los higos -en el caso de Peña Moñuz- y el vino -en el caso de la necrópolis de la Cerrada de los Santos de Aragoncillo (Arenas y Cortés 1994: 7).

Si a esto añadimos que es también en estos momentos cuando algunos de los enclaves en altura parecen constituirse en los núcleos de residencia principal, podríamos pensar que nos encontramos ante una incipiente polarización social del hábitat. Lo que es difícil de discernir todavía es en qué términos quedó establecida esa diferenciación. A nivel interno no se reconocen en los poblados diferencias de rango o poder adquisitivo, y si tenemos en cuenta que los asentamientos en llano debieron soportar el peso de la producción primaria -explotaciones agropecuarias y minero-metalúrgicas- cabría pensar que tal jerarquización sería relativa porque, al menos en el ámbito económico, siguió existiendo una relación de reciprocidad entre los poblados en altura y en llano. Pero frente a esta interpretación cabe oponer una objeción importante: si volvemos la mirada al cuadro de la Figura 2, podremos advertir que es en esta época cuando se registra la mayor diferenciación de los objetos de prestigio personal en los ajuares funerarios, paralela a la ya comentada intensificación productiva.

¿Cómo interpretar esta concurrencia de factores? Pues admitiendo que, a pesar de las novedades comentadas, los cambios acaecidos en esta etapa no se operan tanto en los patrones generales de poblamiento como en los cuadros económicos y sociales sostenidos en el interior los asentamientos. Unos cambios que, en el plano económico podrían quedar resumidos en el paso de unos modos domésticos de producción a estrategias económicas tendentes a la intensificación productiva y la redistribución; y en el plano socio-político en la transición desde una sociedad de tipo tribal hacia otra de tipo jefatura que reclama, entre otras cosas, estructuras de poder más centralizadas.

\section{Los oppida y la política: hacia la disolución del orden tradicional}

En las etapas finales de la Edad del Hierro se detecta una nueva vertebración del poblamiento 
caracterizada por la reducción del número absoluto de asentamientos aunque paralela a un incremento de las diferencias en cuanto a su tamaño. Ahora la diversificación funcional es manifiesta, pues las distintas modalidades de hábitat reflejan tanto una nítida especialización económica como un acusado particularismo social.

El poblamiento en altura experimenta significativas transformaciones, ya que junto a los tradicionales asentamientos segmentarios aparecen centros de mayor envergadura $-\mathrm{y}$ mayor rango socio-económico- que presentan notables innovaciones: asentamientos como Los Rodiles de Cubillejo de la Sierra, con más de cinco hectáreas de extensión, adoptan en su interior un urbanismo de tipo ortogonal y se dotan de unos sistemas defensivos de proporciones descomunales (Cerdeño et al. 2008: 181), probablemente enfocadas ya no tanto a la defensa como a la ostentación social y política. Estos oppida debieron controlar extensos territorios, pues además de alojar una parte importante de la población, capitalizaron un complejo sistema de poblamiento subsidiario. Prueba de ello es que es en estos momentos cuando, por primera vez, puede reconocerse una amplia red de atalayas encaminadas al control de puntos de interés económico y/o estratégico específico paralela a la instalación de un sistema de nodos de comunicación encargados del control visual de amplios territorios (Arenas 1999a: 217 y ss.).

Al mismo tiempo, se constata la traslación de al menos una parte de la producción artesanal hacia el hinterland de estos oppida de manera que, diseminados por el territorio, proliferan una serie de enclaves en llano tanto abiertos como fuertemente defendidos. Entre los primeros se han podido reconocer actividades productivas especializadas como la alfarería (Arenas Esteban 1991-92) o la fundición y primer refinado del metal (Arenas 1999a: 217). Entre los segundos aparece un nuevo tipo de enclave que, ejemplificado en casos como El Castellar de Berrueco (Polo y Villagordo 2004) y otros establecimientos similares (Martínez Naranjo 2002), parecen definir un entramado de unidades autosuficientes, al menos en el plano subsistencial y productivo. Su reducido tamaño, las potentes murallas de las que se rodean-que tampoco ahora tienen un carácter defensivo porque en la mayoría de las ocasiones son asentamientos en llano fácilmente expugnables-, su estrecha relación con áreas de alto potencial económico -ya sea agrícola o metalúrgico-y su lejanía respecto a las áreas de poblamiento denso y vías de comunicación principal, reflejan un alto interés por la individualización y la exclusión social.

Todos estos elementos indican que si en los momentos iniciales de la Edad del Hierro el espacio interior de los asentamientos es compartido y, a lo sumo, organizado en ámbitos de diferente funcionalidad, en las fases más avanzadas, la sociedad se organiza de otra manera.

Por una parte la población tiende a concentrarse, lo que exige, o es propiciado por, una intensificación agraria y, en general, de las estrategias económicas excedentarias perceptibles en la proliferación tanto del utillaje agrícola en hierro como de las grandes vasijas para el almacenaje de productos sólidos. El urbanismo ortogonal y la insularización que éste conlleva hacen que la sociedad se "encierre" en unidades mucho más privadas dentro de los propios asentamientos; una nueva organización espacial que pudo incentivar un aumento de la individualización y, por consiguiente, de la tensión social.

Paralelamente, la especialización en el plano productivo y la dispersión de una parte de la población al objeto de maximizar el acceso a diversos recursos también provoca un aumento del individualismo que queda plasmado en las "pequeñas fortalezas" que, como El Castellar de Berrueco, no son otra cosa que explotaciones de carácter familiar. Pero una familia es un contingente insuficiente para mover los inmensos bloques que conforman su muralla; fue necesario algo más: el flujo de trabajo conjunto que proporciona la unidad emanada de constructos socio-políticos de mayor amplitud que la tribu o la jefatura.

Aparición de poblados de grandes dimensiones junto a la multiplicación de pequeños asentamientos; nucleación versus dispersión del poblamiento... ¿qué está pasando?

Pues que el área Alto Tajo-Alto Jalón queda integrada por entonces en dinámicas culturales de mucha mayor amplitud de lo que había estado hasta el momento. Este proceso, aparentemente contradictorio, está relacionado con la aparición y consolidación del fenómeno urbano en las zonas bajas del Sistema Ibérico y la 
Meseta oriental; un fenómeno de carácter endógeno que se inicia con los reajustes socioeconómicos que tuvieron lugar a lo largo de los siglos IV-III a.C. y deriva hacia un nuevo orden de corte proto-estatal, como indican la aparición de la escritura, la estandarización de pesos y medidas (García y Bellido 2005), la acuñación y amplia circulación de moneda (Burillo 2007) e, incluso, la aparición de las primeras leyes de alcance intercomunitario (De Bernardo-Stempel 2010).

En la zona que nos ocupa tales innovaciones se manifiestan en diversos registros:

a) la emergencia de sistemas sociales estructuralmente más complejos y fragmentados, con una creciente tendencia hacia la individualización y la autosuficiencia de las unidades básicas de residencia/producción.

b) esto, a su vez, determina la desarticulación del modelo socio-económico hasta entonces representado por los grupos segmentarios residentes en los asentamientos fortificados.

c) la emergencia de un modelo político de tipo poliado va a determinar también la disolución de las tradicionales relaciones de parentesco y transmisión hereditaria y, con ellas, alguna de sus vías de expresión tradicional como fue la demarcación social a través de sus ajuares funerarios, que a partir de entonces desaparecen casi por completo de las sepulturas (Ruiz Gálvez 1990).

Los estadios finales de este proceso acaban solapándose con otro evento histórico trascendental: la romanización de la península Ibérica, cuyo avance dio lugar a un sorprendente cambio, no sólo en las formas, sino en los contenidos sociales y económicos del mundo indígena.

Por lo que respecta a los sistemas de poblamiento, la integración del tejido indígena en el Estado romano se canalizó a través de un sistema municipal basado en ciudades de distinto rango y sus correspondientes agri, cuya gestión directa recaía sobre las villae y los vici. La contundencia de esta nueva situación es tal que su huella material determina el paisaje humano de una buena parte de la Península en torno al cambio de Era. Aunque existen excepciones, y el área Alto Tajo-Alto Jalón es una de ellas.

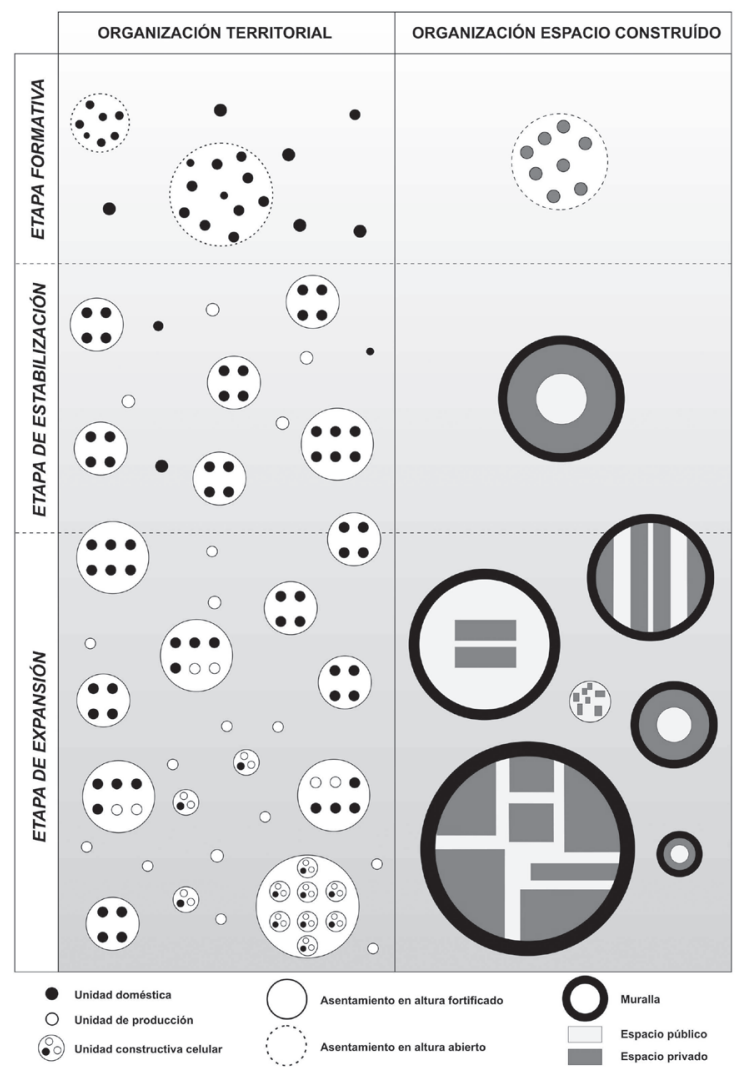

Figura 6.- Esquema evolutivo de los patrones de poblamiento y la configuración de los entornos construidos protohistóricos en el área Alto TajoAlto Jalón.

En esa zona la práctica totalidad de los asentamientos indígenas se abandonan entre mediados del siglo I a.C. y mediados del I d.C. Pero, al contrario de lo que cabría esperar, no se ha constatado un poblamiento de nueva planta capaz de alojar a la población desplazada: a excepción de Arcobriga y Ocilis, no se conocen ciudades de época romana -de hecho no se desarrollarán hasta la plena Edad Media-; en el mismo sentido, tampoco progresó un sistema de villae y, con ellas, el modelo económico que representan. Desde el cambio de Era, el esquema de poblamiento en el Alto Tajo-Alto Jalón se reduce a un escaso número de antiguos poblados en altura reocupados, a algunas aldeas de muy modesta extensión $\mathrm{y}$, en la mayoría de los casos, a minúsculas instalaciones frecuentemente asociadas a escoriales que hacen pensar en su enfoque eminentemente metalúrgico. 
La lectura que cabe hacer de este panorama es que hacia el cambio de Era las estructuras sociales y productivas del mundo indígena habían quedado desarticuladas, lo que provoca el colapso del modelo de poblamiento tradicional. Esto, a su vez, debió provocar que una parte de la población se desplazase -voluntaria o forzosamente- hacia las zonas urbanizadas, y que la población estante quedase fragmentada en pequeñas unidades de producción. El poblamiento queda así atomizado en pequeñas células dispersas por el territorio de forma que, una vez más, su visibilidad arqueológica queda sensiblemente mermada.

Tal panorama se prolongará hasta que el sistema urbano de época clásica entre en crisis. Y no será hasta la Alta Edad Media cuando la población local volverá a reagruparse, curiosamente, en los antiguos castros protohistóricos, a tenor de unos esquemas socio-económicos de tipo descentralizado basados en la ganadería de tipo intensivo.

Con este somero recorrido espero haber argumentado de forma mínimamente satisfactoria que, lejos de estar ante un panorama uniforme de "castros" y "guerreros", el poblamiento protohistórico en el área del Alto Tajo-Alto Jalón es un fenómeno complejo, rico en matices, e interconectado con otros parámetros que lo condicionan y a los que condiciona.

Efectivamente, el registro arqueológico muestra que tanto la articulación territorial como la configuración interna de esos asentamientos aparentemente similares en lo que respecta a su fisonomía externa- han variado sensiblemente a lo largo del tiempo; un proceso plasmado en la Figura 6, que sintetiza las transformaciones experimentadas por los patrones de asentamiento y los entramados urbanos en función de los diferentes contextos sociales y económicos que se sucedieron durante la Edad del Hierro.

A escala regional, podemos observar que a lo largo del tiempo esos enclaves fortificados mantienen una relación cambiante con los asentamientos en llano que los rodean, que desde la instauración del poblamiento estable dejan de ser el núcleo básico del poblamiento para ocupar un papel subsidiario o, al menos complementario, de los primeros.

Junto a los cambios en los patrones de implantación territorial, asistimos a importantes transformaciones en la organización interna de esos poblados y las unidades constructivas que los componen. Estamos ante "espacios construidos" que constan de áreas de vivienda, de almacenaje y de producción artesanal cuya fisonomía también ha variado a lo largo del espacio y el tiempo. Y si aceptamos que los atributos físicos de los asentamientos son elementos mnemotécnicos que recuerdan a la gente el comportamiento apropiado para hacer posible la coacción social (Rapoport 1998: 462), deberíamos igualmente aceptar que los habitantes de aquellos poblados no siempre estuvieron sujetos a los mismos principios organizativos.

Desde esta perspectiva, las diferencias que hemos venido analizando pueden ser atribuidas a variaciones en la estructura del aparato productivo y de los mecanismos de reproducción social, respondiendo a necesidades concretas que pudieron ser expresadas mediante un lenguaje tanto práctico como simbólico.

Ejemplo de esto último es el hecho de que, por lo común, muchos de aquellos asentamientos se rodearon de muros perimetrales que han sido habitualmente interpretados como un mero recurso defensivo. Pero es conveniente señalar que además de defensa, la delimitación del espacio habitado mediante barreras arquitectónicas le proporciona un alto grado de cohesión interna -tanto urbanística como social- y permite a sus ocupantes la afirmación de su identidad comunitaria (Fernández Posse y Sánchez Palencia 1998: 129). De este modo, las pretendidas murallas pueden convertirse en elementos simbólicos cuya función pudo evolucionar desde, u oscilar entre, la de aislamiento social a la de indicador de estatus. En el primer caso actuarían como una barrera de exclusión social definiendo grupos concretos en el seno de un entorno social más amplio (Hingley 1990); en el segundo formarían parte de un código de comunicación no verbal concebido para expresar el estatus social de la comunidad residente (Bowden y McOmish 1987: 77; Myrtum et al. 1996). Con esto quiero decir que no podemos atribuir el mismo significado a una muralla como la de El Ceremeño -que posiblemente tuvo en origen una función eminentemente simbólica- con la de Peña Moñuz - con una proyección básicamente defensiva- o con la de El Palomar, que fue básicamente cons- 
truida para garantizar la estabilidad estructural del conjunto urbano.

En definitiva, lo que queda reflejado en la progresiva transformación de los sistemas de poblamiento en el Alto Tajo-Alto Jalón es un proceso de cambio social. La historia podría resumirse más o menos como sigue: partiendo de unos planteamientos en cierto modo igualitarios relacionados con esquemas organizativos de tipo tribal, la sociedad se encaminó hacia la desigualdad y la apropiación del territorio características de los sistemas jefatura, para acabar en el indivi- dualismo y la parcelación del espacio construido a las que condujo una organización de tipo protoestatal adoptada, al menos, desde los inicios del siglo II a.C.

No sé como hubiese acabado esta historia si hubiese seguido su curso natural, porque "llegaron los romanos"... Lo que sí sé es que aquella sociedad se vio profundamente transformada; tanto que -utilizando una idea ya expresada en un trabajo anterior-su identidad ya nunca más pudo ser expresada en las murallas de sus poblados o en el paisaje funerario de sus necrópolis.

\section{REFERENCIAS BIBLIOGRÁFICAS}

Almagro Gorbea, M.; DÁvila, A. (1988): Estructura y reconstrucción de la cabaña «Ecce Homo 86/6». Espacio, Tiempo y Forma, Serie I, Prehistoria 1: 361-374.

Almagro Gorbea, M.; Fernández-Galiano, D. (1980): Excavaciones en el cerro Ecce Homo (Alcalá de Henares, Madrid). Arqueología, 2, Diputación provincial de Madrid.

Arenas Esteban, J. A. (1991-1992): El alfar celtibérico de "La Rodriga". Fuentelsaz, Guadalajara. Kalathos, 11-12: 205-232.

Arenas Esteban, J. A. (1997): La génesis de la cultura celtibérica en el área Alto Tajo-Alto Jalón: ¿continuidad o ruptura? Celtas y Celtíberos: realidad o leyenda. Unión Cultural Arqueológica, Madrid: 114-141.

Arenas Esteban, J. A. (1999a): La Edad del Hierro en el Sistema Ibérico Central, España. B.A.R., International Series S780, Oxford.

Arenas Esteban, J. A. (1999b): El inicio de la Edad del Hierro en el sector central del Sistema Ibérico. El Origen del Mundo Celtibérico (J. A. Arenas, M.V. Palacios, eds.), Ayuntamiento de Molina de Aragón, Guadalajara: 191-211.

Arenas Esteban, J. A. (1999c): Comercio protohistórico: líneas de contacto entre Levante y el Sistema Ibérico. IV Simposio sobre Celtíberos: Economía (F. Burillo, ed.), Institución Fernando el Católico, Zaragoza: 301-309.

Arenas Esteban, J. A. (2004): La influencia del mundo paleopúnico en la Meseta oriental. El Mundo Púnico. Religión, antropología y cultura material (A. González Blanco, G. Matilla Séiquer, A. Egea Vivancos, eds.), Estudios Orientales, 5-6, Murcia: 157-171.

Arenas Esteban, J. A. (2007): Sociedad, ideología y entornos construidos durante la Protohistoria del oriente meseteño: el caso de El Ceremeño de Herrería. Trabajos de Prehistoria, 64-1: 121-136.

Arenas Esteban, J. A. (2009): Arquitectura doméstica y sociedad en contextos prerromanos del oriente meseteño. L'epai domèstic i l'organizatzió de la societat a la protohistoria de la Mediterrània occidental (Ier millenni a. C.) (M. C. Belarte, ed.), Departament de Prehistoria, Historia Antigua i Arqueologia de la Universitat de Barcelona, Barcelona: 149-163.

Arenas Esteban, J. A. (2010): Arquitectura doméstica prerromana en el oriente meseteño: análisis funcional y estimaciones demográficas. Arqueología de la Población (F. Burillo Mozota, ed.), Arqueología Espacial, 28, Teruel: 335-349.

Arenas Esteban, J.; Martínez Naranjo, J. P. (1993-1995): Poblamiento Prehistórico en la Serranía Molinesa: "El Turmielo" de Aragoncillo (Guadalajara). Kalathos, 13-14: 89-141.

Arenas Esteban, J. A.; Cortés, M. L. (1994): Mortuary rites in the Celtiberian cemetery of Aragoncillo (Guadalajara, Spain). Ritual, Rites and religion in Prehistory. IIIrd Deya International Conference of Prehistory (W.H. Waldren, J.A. Ensenyat, R.C. Kennard, eds.), B.A.R., International Series 611, II, Oxford: 1-20. 
Arlegui, M. (1992): El yacimiento celtibérico de Castilmontán, Somaén (Soria): El Sistema defensivo. II Symposium de Arqueología Soriana (Soria 1989), Tomo I, Diputación provincial de Soria, Soria: 495-513.

Barroso, R.M.; DíAz, C. (1999): El castro del Hocincavero, Anguita, Guadalajara. Un avance de sus excavaciones. El Origen del Mundo Celtibérico (J. A. Arenas, M.V. Palacios, eds.), Ayuntamiento de Molina de Aragón, Guadalajara: 98-101.

Blasco Bosqued, M.C. (2007): El tránsito del Bronce Final al Hierro Antiguo en la cuenca baja del Manzanares. Estudios sobre la Edad del Hierro en Carpetania (A. Dávila, ed.), Zona Arqueológica 10 (1), Museo Arqueológico Regional, Alcalá de Henares: 65-86.

Bowden, M.; Mcomish, D. (1987): The required barrier. Scottish Archaeological Review, 4: 76-84.

Burillo, F. (2007): Los Celtíberos. Etnias y Estados. Crítica, Barcelona (Edición revisada).

Burillo, F.; Ortega, J. (1999): El proceso de formación de las sociedades campesinas en el Sistema Ibérico (1400-400 a.C.): algunas consideraciones acerca del concepto de «ruptura». El Origen del Mundo Celtibérico (J. A. Arenas, M. V. Palacios, eds.), Ayuntamiento de Molina de Aragón, Guadalajara: 123-140.

Castro Martínez, P. V.; Lull, V.; Micó, R. (1996): Cronología de la Prehistoria Reciente de la Península Ibérica y Baleares (c. 2800-900 cal ANE). BAR International Series 652, Oxford.

Cebolla Berlanga, J. L. (1992-1993): El tránsito del Bronce Final a la primera Edad del Hierro en el sector NW de la cuenca del Jalón. Bajo Aragón Prehistoria IX-X: Segundos Encuentros de Prehistoria Aragonesa. Caspe: 175-191.

Cerdeño, M. L.; García Huerta, M. R. (1992): El castro de La Coronilla, Chera, Guadalajara (1980-1986). Excavaciones Arqueológicas en España, 163, Madrid.

Cerdeño, M. L.; García Huerta, R.; Baquedano, I.; Cabanes, E. (1996): Contactos interior-zonas costeras durante la Edad del Hierro: los focos del noreste y suroeste meseteños. Homenaje al Profesor Manuel Fernández-Miranda (M‥ A. Querol, T. Chapa, eds.), Complutum, Extra 6 (I): 287-312.

Cerdeño, M. L.; Juez, P. (2002): El Castro Celtibérico de "El Ceremeño" (Herrería, Guadalajara). Seminario de Arqueología y Etnología Turolense, Junta de Comunidades de Castilla-La Mancha, Teruel.

Cerdeño, M. L.; SAgardoy, T. (2007): La necrópolis celtibérica de Herrería III y IV (Guadalajara). Fundación Segeda-Centro de Estudios Celtibéricos-Junta de Comunidades de Castilla-La Mancha. Zaragoza.

Cerdeño, M. L.; T. Sagardoy; M. Chordé; E. Gamo (2008): Fortificaciones celtibéricas frente a Roma: el oppidum de Los Rodiles (Cubillejo de la Sierra, Guadalajara). Complutum, 19: 173-189.

Crespo Cano, M. L.; Arenas Esteban, J. A. (1998): Aproximación a la secuencia cultural del Bronce Final y Primer Hierro en las tierras de Guadalajara (I). Actas del VI Encuentro de Historiadores del valle del Henares, Alcalá de Henares: 47-73.

De Bernardo-Stempel, P. (2010): La ley del 1er Bronce de Botorrita: uso agropecuario de un encinar sagrado. VI Simposio sobre los Celtíberos: Ritos y Mitos (F. Burillo, ed.), Fundación Segeda-Centro de Estudios Celtibéricos, Zaragoza: 123-145.

Fernández-Posse, M. D.; SÁnChez-PALEnCiA, F. J. (1998): Las comunidades campesinas en la cultura castreña. Trabajos de Prehistoria, 55 (2): 127-150.

García y Bellido, M. P. (2005): La metrología ponderal: dinero y moneda. Celtíberos. Tras las huellas de Numancia (A. Jimeno, ed.), Diputación provincial de Soria, Soria: 381-386.

Hingley, R. (1990): Domestic organization and gender relations in Iron Age and Romano-British households. The social archaeology of houses (R. Samson, ed.), Edimburgo: 125-147.

IBÁÑEz GonzÁlez, J. (1999): Evolución de la potencialidad agrotérmica en la Celtiberia durante la Edad del Hierro. IV Simposio sobre Celtíberos: Economía (F. Burillo, ed.), Institución Fernando el Católico, Zaragoza: 11-46.

Iglesias Vecino, E.; Arenas Esteban, J.; Cuadrado Prieto, M.A. (1989): La ciudad fortificada de "La Cava" (Luzón, Guadalajara). Wad-Al-Hayara, 16: 75-100.

Jimeno Martínez, A.; Arlegui Sánchez, M. (1995): El poblamiento del Alto Duero. III Simposio sobre los Celtíberos: El poblamiento celtibérico (F. Burillo Mozota, coord.), Institución Fernando el Católico, Zaragoza: 93-126. 
Martín Bañón, A. (2007): Espacios domésticos y de almacenaje en la confluencia de los ríos Jarama y Manzanares. Estudios sobre la Edad del Hierro en Carpetania (A. Dávila, ed.), Zona Arqueológica, 10 (II), Museo Arqueológico Regional, Alcalá de Henares: 27-41.

Martínez Naranjo, J. P. (1997): El inicio del mundo celtibérico en el interfluvio Jalón-Mesa. Complutum, 8: $161-182$.

Martínez Naranjo, J. P. (2002): Las murallas ciclópeas prerromanas de la zona oriental de Guadalajara. Actas del I Simposio de Arqueología de Guadalajara (E. García-Soto, M. A. García Valero, eds.), Madrid: 401-411.

Martínez Naranjo, J. P.; Arenas Esteban, J. A. (1999): La explotación del hierro en el curso alto del río Mesa (Guadalajara) en época celtibérica. IV Simposio sobre Celtíberos: Economía (F. Burillo, coord.), Institución Fernando el Católico, Zaragoza: 203-207.

Martínez Sastre, V. (1992): El poblado de Campos de Urnas de Fuente Estaca (Embid, Guadalajara). La celtización del Tajo Superior (J. Valiente Malla, ed.), Memorias del Seminario de Historia Antigua de la Universidad de Alcalá de Henares, III, Alcalá de Henares: 67-78.

Méndez Madariaga, A.; Velasco Steigrad, F. (1988): La Muela de Alarilla. I Congreso de Historia de Castilla-La Mancha, Tomo III, Ciudad Real: 185-195.

Misiego Tejeda, J.C.; Marcos Contreras, G.J.; Martín Carbajo, M.A.; Sanz García F.J.; Villanueva MarTín, L.A. (2005): Guaya (Berrocalejo de Aragona, Ávila): reconstrucción de la vida y economía de un poblado en los albores de la Edad del Hierro. Bronce Final y Edad del Hierro en la Península Ibérica (A. Blanco, C. Cancelo, A. Esparza, eds.), Encuentro de Jóvenes Investigadores. Universidad de Salamanca, Salamanca: 207-228.

Myrtum, H.; Gathercole, C.; Fenwick, H. (1996): Hillfort sitting and monumentality: Castell Henllys and geographical information systems. Archaeology in Wales, 36: 3-10.

Ortega, J. (1999a): Microespacio y Microhistoria: La Arqueología del espacio doméstico. Arqueología Espacial, 21: 101-115.

ORTEGA, J. (1999b): Al margen de la «identidad cultural»: historia social y económica de las comunidades campesinas celtíberas. IV Simposio sobre Celtíberos: Economía (F. Burillo, ed.), Institución Fernando el Católico, Zaragoza: 417-452.

Polo Cutando, C.; Villagordo Ros, C. (2004): Del poblado fortificado al asentamiento en llano: La evolución de los asentamientos rurales en el Sistema Ibérico central (s. IIIa.C.-I d.C.). Torres, atalayas y casas fortificadas. Explotación y control del territorio en Hispania (s. III a.C.-s. I d.C) (P. Moret, T. Chapa, eds.), Universidad de Jaén: 157-173.

RAPOPORT, A. (1998): Spatial organization and the built environment. The Companion Encyclopedia of Anthropology (T. Ingold, ed.), Routledge, Londres-Nueva York: 460-502.

Romero Carnicero, F. (1999): Orígenes y evolución del grupo castreño de la Sierra Norte Soriana. El Origen del Mundo Celtibérico (J. A. Arenas, M. V. Palacios, eds.), Ayuntamiento de Molina de Aragón, Guadalajara: 144-164.

ROVIRA I PORT, J. (1990-1991): Reflexiones sobre los primeros campos de urnas en la Península Ibérica: una arribada marítima. Cuadernos de Prehistoria y Arqueología Castellonense, 15: 157-171.

Ruiz-Gálvez, M. L. (1990): Propuesta para el estudio e interpretación de las necrópolis sin armas. II Simposio sobre los Celtiberos: Las Necrópolis Celtibéricas (F. Burillo, coord.), Institución Fernando el Católico, Zaragoza: 343-347.

Sanmartí, J.; Santacana, J. (2005): Els Ibers del Nord. Ed. Rafael Dalmau, Barcelona.

Schule, W (1969): Die Mesetakulturen der Iberischen Halbinsel. Madrider Forschungen, 3.

Urbina, D.; Morín, J.; Ruiz, L.A.; Agustí; E.; Montero, I. (2007): El yacimiento de Las Camas, Villaverde, Madrid. Longhouses y elementos orientalizantes al inicio de la Edad del Hierro en el valle medio del Tajo. Gerión, 25: 45-82. 